Dos mujeres en el siglo de la radio

Mario Giorgi

Question/Cuestión, Vol. 2, № 66, Agosto 2020

ISSN 1669-6581

https://perio.unlp.edu.ar/ojs/index.php/question/index

IICom-FPyCS-UNLP

\title{
DOS MUJERES EN EL SIGLO DE LA RADIO
}

\section{TWO WOMEN IN THE CENTURY OF THE RADIO}

\section{Loc. Mario Giorgi}

Director de Medios de la Universidad Nacional de Avellaneda y Conductor del programa Llega el Día por Radio Nacional AM 870 mgiorgi@undav.edu.ar

\section{Resumen}

Mario Giorgi recupera en dos entrevistas la vida profesional de dos excelentes locutoras, Nora Perlé y Betty Elizalde que han dejado una marca indiscutible en la radio argentina.

\section{Palabras clave}

Locutoras, Radio, Profesión, Excelencia 


\begin{abstract}
Mario Giorgi recovers in two interviews the professional lives of two excellent female presenters, Nora Perlé and Betty Elizalde, who have left an indisputable mark on Argentine radio.
\end{abstract}

\title{
Keywords
}

Broadcasters - Radio - Profession - Excellence

\section{Introducción}

Contemporáneas, tan parecidas y tan distintas. Juntas egresaron del ISER como locutoras, apenas rondaban los 18 o 20 años. Fueron compañeras y hasta se superpusieron y reemplazaron en programas cargados de historias, momentos de radio inolvidables.

A Deolinda Beatriz Bistagnino y Lidia Nora Zisman, las juntó la radio y tal vez, de no haber sucedido la noche oscura de la dictadura cívico-militar del 76, les habría tocado junto a Nucha Amengual, la pionera Lidia Saporitoi, el punto de partida de una reivindicación que continúa vigente y que salvo honrosas excepciones, le adeuda a la mujer la responsabilidad de poder estar al frente, con un rol central en los medios de comunicación. Los 100 años de la radio les guardan un lugar preponderante.

Deolinda y Lidia, también coincidían en usar su segundo nombre, ya en los comienzos de su carrera locutoril. Beatriz (Betty) y Nora. Una de las historias de oro de la radio es la que las une en el programa "Las siete lunas"ii (1974) auspiciado por la empresa argentina de perfumería masculina Crandall y nacido del genio creativo de Julio Moyano dueño del formato y de la idea. 
Deolinda Beatriz Bistagnino, más conocida como Betty Elizalde cuenta sobre ese ciclo: "Yo llegaba al estudio de grabación con los textos de escritores como Eduardo Gudiño Kieffer. Pero los leía sin decir a quien pertenecían porque para muchos de ellos era como una deshonra, era bajar un escalón. La prensa gráfica y los literatos no querían saber nada con la radio".

Mujeres al frente de programas que a priori se podrían criticar por cierta superficialidad, muy musicales, textos algo pasatistas y mujeres en la conducción, casi susurrando, que sin embargo estaban al frente de una estructura de trabajo con precisión fundamental para la calidad y las exigencias de aquel tiempo.

Betty, además condujo noticieros e informativos en los '70 y '80; pasó por el mítico programa radial "La gallina verde", y ganó dos Martín Fierro, dos premios Zebra de Oro, un Premio Konex y el Premio de la Sociedad Argentina de Locutores. Murió en 2018.

Lidía Nora Zisman, más conocida como Nora Perlé, (aún en el aire con 80 años) la reemplazó a Betty en "Las 7 Lunas" y pasó por casi todas las radios (Libertad, Excelsior, Rivadavia, Continental, Del Plata, Radio de la Ciudad, Nacional y Mitre) y ganó 12 Premios Martín Fierro.

Con las dos, en el aire, arrancó mi modesta carrera profesional y con las dos tuve la oportunidad de hacer el homenaje de la entrevista, en Radio UNDAV, para que cuenten sus historias. Por eso, en los 100 años de la Radio, no se trata de una selección tomada al azar. Fue para tener por siempre sus voces, sus recuerdos, sus penas y alegrías, como dos mujeres pioneras, al frente de su destino para comunicar. Dos "Perfiles en la UNDAV" con vasos comunicantes, memoria emotiva y respeto profesional, para mujeres, que se armaron de fuerza en un mundo todavía de hombres. 
Enlace Betty Elizalde

https://go.ivoox.com/rf/55604615

Enlace Nora Perlé

https://go.ivoox.com/rf/55617940

Notas

'Lidia Saporito fue la primera conductora "sensual" de "Las 7 lunas de Crandall", Nucha Amengual, compañera del ISER de Betty y Nora, condujo, entre otros, el musical "Miss Ylang y su música" programa sostenido económicamente por la línea de cosméticos del mismo nombre.

ii https://www.continental.com.ar/opinion/bloggers/blogs/una-produccion-decontenidos-continental/continental-45-anos-las-siete-lunas-de-crandall-conbetty-elizalde/blog/2426437.aspx 